\title{
PREPARATION AND CHARACTERIZATION OF CATALYST FOR REDUCTION AMINATION OF ETHANOLAMINE BY DIFFERENT METHOD
}

\author{
Li Xin ${ }^{1}$, Wang Huan², Liu Li-Ye' ${ }^{1}$, Zhang Ji-Bo², Qiu Jun ${ }^{1 *}$ \\ ${ }^{1}$ College of Chemtry and Pharmaceutical Engineering, Jilin Institute of Chemical Technology, Jilin 132022, China. \\ ${ }^{2}$ College of Petrochemical Technology,Jilin Institute of Chemical Technology, Jilin 132022, China. \\ *Corresponding Author Email: 2313522164@qq.com
}

This is an open access article distributed under the Creative Commons Attribution License, which permits unrestricted use, distribution, and reproduction in any medium, provided the original work is properly cited

\section{ARTICLE DETAILS}

Article History:

Received 26 June 2018

Accepted 2 july 2018

Available online 1 August 2018

\begin{abstract}
The NiO-CuO-CaO/ $/ \mathrm{Al}_{2} \mathrm{O}_{3}$ composite oxide catalyst was prepared by impregnation method, CO-precipitation method and grinding microwave method with $\mathrm{Al}_{2} \mathrm{O}_{3}$ as carrier, $\mathrm{Ni}-\mathrm{Cu}$ bimetal as active component and $\mathrm{Ca}$ as additive. And their performances were characterized by XRD, SEM, BET and IR. The results show that impregnation method is a suitable method for the preparation of composite oxide catalyst, and the WNiO:WCuO:WCaO =15:3.5:2.0 is determined by EDS analysis. The relatively large BET specific surface areas of $22.08 \mathrm{~cm}^{2} / \mathrm{g}$ and $31.72 \mathrm{~cm}^{2} / \mathrm{g} \mathrm{can} \mathrm{be}$ obtained by impregnation and microwave grinding, separately, while the CO-precipitation yield is only $2.49 \mathrm{~cm}^{2} / \mathrm{g}$. The BJH pore volume of the composite oxide obtained by the above three methods is not very different. The BJH pore size of the composite oxide obtained by impregnation is $2.070 \mathrm{~nm}$, which is relatively small, in theory, it is more suitable for the catalytic reaction of ethanediamine from ethanolamine by reduction amination.
\end{abstract}

\section{KEYWORDS}

Ethanolamine, reduction amination, ethanediamine, composite oxide, catalyst, preparation

\section{INTRODUCTION}

Ethylenediamine (EDA)is an important chemical raw material and fine ch emical intermediate. It is widely used in the fields of pesticides, pharmace uticals and additive. It can be used to produce chelating agents, insect rep ellents, soil conditioners, lubri cants, rubber accelerators, emulsifiers [1-3 ]. The synthesis methods of ethylenediamine mainly include dichloroetha ne method, ethanolamine method, ethylene amination, formaldehyde-hyd rocyanic acid method, etc [4-6]. In recent years, the application of EDA in China has developed rapidly. Its annual growth rate of demand has reach ed $20 \%$,which is one of the fine petrochemical intermediates urgently to b e developed in China [7-9]. At present, the main routes for the production of EDA in industry are dichloroethane (EDC)and ethanolamine (MEA)met hods [10]. Between them, the EDC route has serious pollution and high in vestment costs; while compared with the EDC route, the MEA route show s less pollution and lower investment costs [11-13]. Currently, the EDC ro utes employed are about $61 \%$ of the EDA production facilities in the world , and they will be substituted by the MEA routes, Which will be the genera l trend of development [14-16].

MEA has two reactive functional groups, the reaction with ammonia is $\mathrm{m}$ ore complex. In which, tandem reaction between intramolecular or interm olecular is occurred, and a series of chain or cyclic by-products are genera ted. Above of these results in the reduced selectivity of ethylenediamine [ 17-20]. Therefore, on the process route of EDA from MEA, high-activity an $\mathrm{d}$ high-selectivity catalysts have always been the focus of researchers. In o ur study, the reduction amination catalyst for MEA route was designed an d prepared. Using $\mathrm{Al}_{2} \mathrm{O}_{3}$ as the carrier, $\mathrm{Ni}-\mathrm{Cu}$ as dual active component and Ca as the additive, the effect of different preparation methods on the perf ormance of the catalyst was investigated. It is hoped that this study will $p$ rovide a useful reference for the research work of catalytic synthesis of $\mathrm{E}$ DA.

\section{EXPERIMENT}

\subsection{Materials}

Active aluminum hydroxide, $\mathrm{Al}(\mathrm{OH})_{3}$, analytically pure (99.0\%),Tianjin Yongda Chemical Reagent Co, Ltd; Aluminum nitrate, $\mathrm{Al}\left(\mathrm{NO}_{3}\right)_{3} \bullet 9 \mathrm{H}_{2} \mathrm{O}$,analytically pure( $\left.99.0 \%\right)$,Tianjin hengxing chemical reagent manufacturing co.LTD;Nickel nitrate, $\mathrm{Ni}\left(\mathrm{NO}_{3}\right)_{2} 6 \mathrm{H}_{2} \mathrm{O}$, analyticallypure $(98.0 \%)$,Tianjin Yongda Chemical Reagent Co.,Ltd;Copper nitrate, $\mathrm{Cu}\left(\mathrm{NO}_{3}\right)_{2} \bullet 3 \mathrm{H}_{2} \mathrm{O}$, analytically pure(99.0\%),Tianjin Ruijinte Chemical Co.,Ltd.;Calcium nitrate, $\mathrm{Ca}\left(\mathrm{NO}_{3}\right)_{2} \bullet 4 \mathrm{H}_{2} \mathrm{O}$, analytically pure $(99.0 \%)$,Tianjin Ruijin Special Chemicals Co.,Ltd.;Anhydrous sodium carbonate, $\mathrm{Na}_{2} \mathrm{CO}_{3}$, analytically pure(99.8\%),Tianjin City Northern Tianyi Chemical Reagent Factory. All reagents were not further purified before use.

\subsection{Instruments}

D8 ADVANCE powder X-ray diffractometer, Bruker AXS Corporation, Germany; JSM-6490LV Scanning Electron Microscope, Japan Electronics Corporation, Japan;Gemini VII 2390 Automatic Surface Area Analyzer, Micromeritics Corporation,USA;Nicolet-6700 Fourier infrared spectrometer, USA Nicolet Corporation, USA.

\subsection{Preparation of catalyst}

\subsubsection{Preparation of carrier}

The active aluminum hydroxide raw materials are clained by a temperature program, the process is as follows: the first stage, heating for $24 \mathrm{~min}$ from room temperature to $260^{\circ} \mathrm{C}$; the second stage, keeping the temperature of $260^{\circ} \mathrm{C}$ for $1 \mathrm{~h}$; the third stage, another heating for 69 minutes, and the temperature was increased to $950^{\circ} \mathrm{C}$; the fourth stage, running to maintain at $950^{\circ} \mathrm{Cfor} 4 \mathrm{~h}$; finally, natural cooling to room temperature. According to above program, he catalyst carrier transition state $\mathrm{Al}_{2} \mathrm{O}_{3}$ is obtained. 


\subsubsection{Impregnation (IMP)}

The above catalyst carrier is added to an ethanol solution of $\mathrm{Ni}$ $\left(\mathrm{NO}_{3}\right)_{2} \bullet 6 \mathrm{H} 2 \mathrm{O}, \mathrm{Cu} \quad\left(\mathrm{NO}_{3}\right)_{2} \bullet 3 \mathrm{H}_{2} \mathrm{O}, \mathrm{Ca}\left(\mathrm{NO}_{3}\right)_{2} \bullet 4 \mathrm{H}_{2} \mathrm{O}$ in proportion. After magnetic stirring for $2 \mathrm{~h}$, removing the ethanol by rotary evaporator, and then drying at $105^{\circ} \mathrm{Cfor} 4 \mathrm{~h}$, grinding to micron level. The catalyst samples was prepared according to the calcination process of temperature program, and the sample was recorded as No (IMP) [21].

\subsubsection{Coprecipitation (COP)}

$\mathrm{Al}\left(\mathrm{NO}_{3}\right)_{3} \bullet 9 \mathrm{H}_{2} \mathrm{O}(10.3034 \mathrm{~g}), \mathrm{Ni}\left(\mathrm{NO}_{3}\right)_{2} \bullet 6 \mathrm{H}_{2} \mathrm{O}(1.1682 \mathrm{~g}), \mathrm{Cu}\left(\mathrm{NO}_{3}\right)_{2} \bullet 3 \mathrm{H}_{2} \mathrm{O}(0.60$ $74 \mathrm{~g})$, and $\mathrm{Ca}\left(\mathrm{NO}_{3}\right)_{2} \bullet 4 \mathrm{H}_{2} \mathrm{O}(0.4262 \mathrm{~g})$ were mixed to form a homogeneous aqueous solution. Above solution was added a concentrated solution of $\mathrm{Na}_{2} \mathrm{CO}_{3}(9.6116 \mathrm{~g})$. After magnetic stirring for $2 \mathrm{~h}$, the obtained suspension was filtered. Then drying the filter cake, grinding and calcination according to the above method, the catalyst sample was prepared as No (COP) [22].

\subsubsection{Microwave grinding (MWG)}

$\mathrm{Al}\left(\mathrm{NO}_{3}\right)_{3} \bullet 9 \mathrm{H}_{2} \mathrm{O}(10.3034 \mathrm{~g}), \mathrm{Ni}\left(\mathrm{NO}_{3}\right)_{2} \bullet 6 \mathrm{H}_{2} \mathrm{O}(1.1682 \mathrm{~g}), \mathrm{Cu}\left(\mathrm{NO}_{3}\right)_{2} \bullet 3 \mathrm{H}_{2} \mathrm{O}(0.60$ $74 \mathrm{~g})$, and $\mathrm{Ca}\left(\mathrm{NO}_{3}\right)_{2} \bullet 4 \mathrm{H}_{2} \mathrm{O}(0.4262 \mathrm{~g})$ four kinds of nitrate solid were mixed in proportion. After grinding, the mixture was placed into the microwave synthesizer, and reacted under 300W microwave for $15 \mathrm{~min}$. After calcinations and grinding, the catalyst was obtained, and recorded as No (MWG) [23].

\subsection{Characterization of catalyst}

\subsubsection{Powder X ray diffraction analysis (XRD)}

About 1g catalyst sample was ground into powder, loaded the sample plate, pressed flat with glass and placed on the sample rack. Used CuKaas the ray source $(K \alpha=0.15416 \mathrm{~nm})$, NaI Scintillation counter, scan voltage and current were set to $40 \mathrm{kV}$ and $40 \mathrm{~mA}$ respectively.20scanning range was 4 to $65^{\circ}$,step scan mode was employed and step width was $0.02^{\circ}$.The analysis was carried out with $0.1 \mathrm{~s} / \mathrm{step}$ speed. The software of Jade 5.0 was used for corresponding calculations.

\subsubsection{Scanning electron microscopy-energy dispersive spectrometer analysis (SEM-EDS)}

A little powder of catalyst sample was added to the anhydrous ethanol, dispersed under ultrasonic oscillation. And then it was dropped onto a piece of iron attached with a conductive tape. After anhydrous ethanol volatilized, the morphology was observed by using scanning electron microscopy. The operating conditions are as follows: working distance 10 $\mathrm{mm}$, objective lens aperture $100 \mu \mathrm{m}$, sample current 50×10-10 mA, and acceleration voltage $20 \mathrm{kV} . \mathrm{Si}$ (Li)detector was used on the energy spectrometer, the resolution was better than $133 \mathrm{eV}$, the effective detection area was $10 \mathrm{~mm}^{2}$, and the energy spectrum element analysis range was B5 U92.

\subsubsection{BET surface area, BJH pore volume, and BJH size analysis (BET)}

The sample tube was weigh accurately, and about $0.25 \mathrm{~g}$ of the catalyst put in the sample tube. Then the sample was treated under the condition of $90^{\circ} \mathrm{Cfor} 1 \mathrm{~h}$ and $340^{\circ} \mathrm{C}$ for $3 \mathrm{~h}$ in the presence of nitrogen, and the total weight was weigh accurately. The sample tube was fixed to the full automatic surface area meter. Used $99.99 \%$ of $\mathrm{He}$ as carrier gas and $99.999 \%$ of $\mathrm{N}_{2}$ as adsorbent, the average adsorption and desorption time for each sample at $\mathrm{P} / \mathrm{P}_{0}$ was $5 \mathrm{~min}$. Empty rate was $300 \mathrm{mmHg} / \mathrm{min}$, balance time was $5 \mathrm{~s}$, and 9-point analysis was run. The specific surface area was calculated by BET method, the pore size and distribution of samples and the pore volume of samples were analyzed by BJH method.

\subsubsection{Infrared spectroscopic analysis (IR)}

The sample was dried in a vacuum and ground into a powder, determined by solid $\mathrm{KBr}$ pressing method (the mass ratio of $\mathrm{KBr}$ to sample $=100: 1$ ), and detected by DTGS medium infrared detector with a resolution of 0.1 $\mathrm{cm}^{-1}$ and measured in the range of 4000 to $450 \mathrm{~cm}^{-1}$, Wave number accuracy $0.01 \mathrm{~cm}^{-1}$.

\section{RESULTS AND DISCUSSION}

\subsection{X-ray diffraction results}

On the basis of $\mathrm{Al}_{2} \mathrm{O}_{3}: \mathrm{NiO}: \mathrm{CuO}: \mathrm{CaO}=70: 15: 10: 5$ (mass percentage) in the catalyst of $\mathrm{NiO}-\mathrm{CuO}-\mathrm{CaO} / \mathrm{Al}_{2} \mathrm{O}_{3}$ composite oxide, the XRD patterns of different catalysts prepared by three methods in the article were shown in Fig.1.The XRD patterns of the individual oxide components were shown in Figure 2.As can be seen from Figure 1 and Figure 2,the complex oxides prepared by the IMP and MWG methods had amorphous phase, separately, while the MGW method was more obvious. Additionally, the characteristic peaks of the oxide crystals can be observed by above two methods, and their crystallinity was similar. However, the composite oxide obtained by COP method was significantly different from the above, the crystallinity was relatively high, and the characteristic peaks of slight oxides can be observed. Some new characteristic peaks appeared indicated that special new phase was generated in the co-precipitation process. It was further confirmed that a large amount of $\mathrm{NaAlO} 2$ metal salt was occurred during precipitation. We can see from the above that, compared with the COP and MGW methods, the IMP method is a suitable method for preparing a composite oxide.

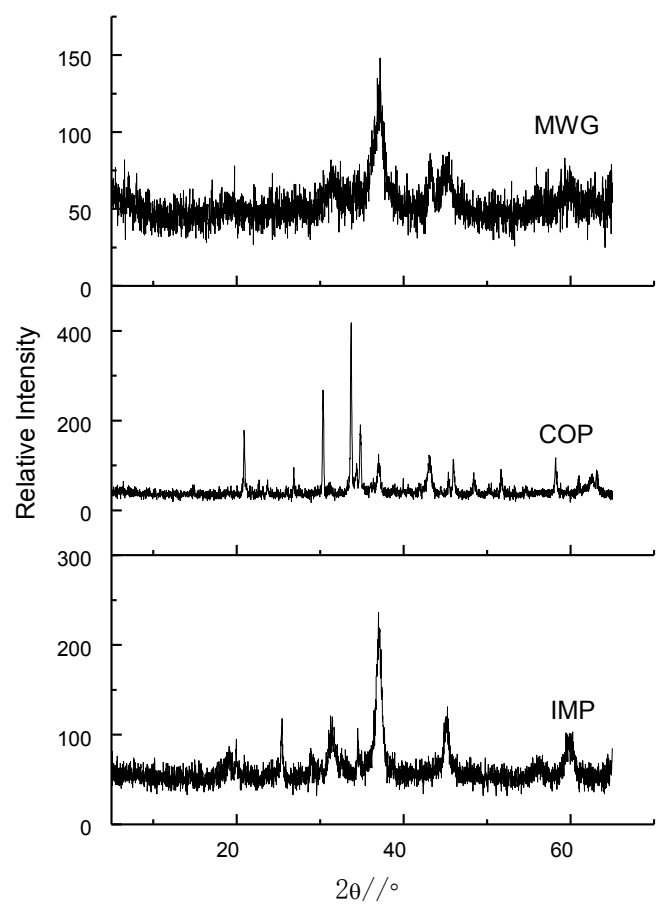

Figure 1: XRD patterns of composite oxides prepared by different methods

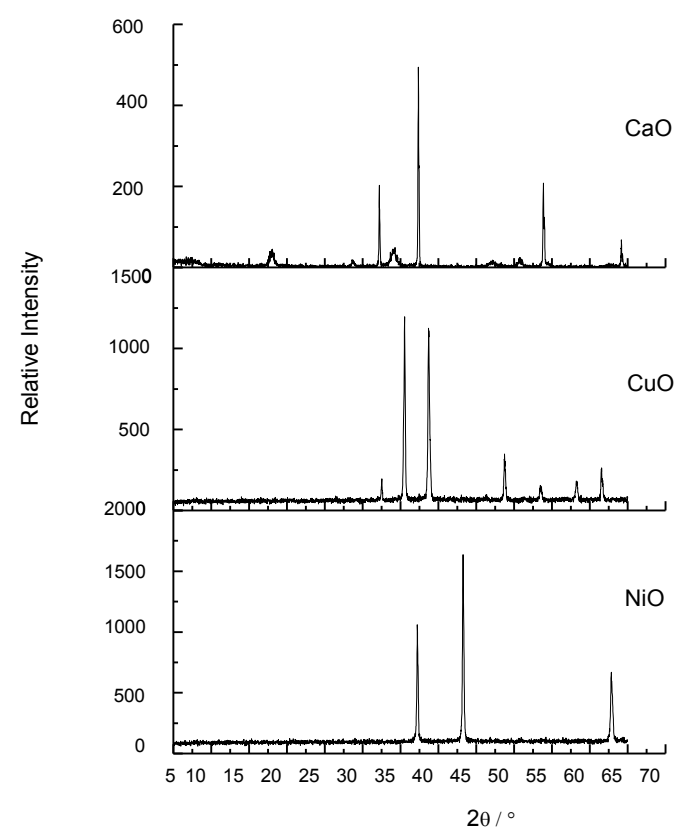

Figure 2: XRD patterns of single oxide 


\subsection{Scanning electron microscope - energy spectrum results}

The SEM images of different composite oxides catalysts prepared by above different methods were shown in Figure 3, and the results of the composite oxides data of EDS analysis were shown in Table 1.
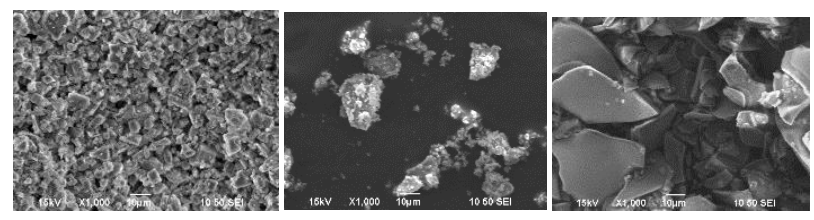

IMP

COP MWG

Figure 3: SEM images of composite oxides prepared by different methods

As shown in Figure 3, there were significant differences in the structure of composite oxides prepared by the three methods. The composite oxides obtained by the IMP method had uniform size, clear contours, loose structure, and rare aggregates. But, by the MWG method, resulted in an extremely inhomogeneous lamellar aggregate structure. While, by the COP method, resulted in larger bulk crystals, and some small particles and flocs were grown on the surface of the bulk crystals.

Table 1: Data of composition of oxides except carriers determined by EDS

\begin{tabular}{|lllllll|}
\hline \multirow{2}{*}{ Preparation } & \multicolumn{3}{l}{ Elemental mass percentage } & \multicolumn{3}{c|}{ Calculate oxide mass ratio } \\
\cline { 2 - 7 } & $\mathrm{Ni}$ & $\mathrm{Cu}$ & $\mathrm{Ca}$ & $\mathrm{W}_{\text {NiO }}$ & $\mathrm{W}_{\text {Cuo }}$ & $\mathrm{W}_{\text {CaO }}$ \\
\hline MWG & 12.509 & 6.808 & 2.571 & 15.0 & 4.9 & 2.1 \\
\hline COP & 11.616 & 2.127 & 5.347 & 15.0 & 1.1 & 4.5 \\
\hline IMP & 17.017 & 7.906 & 3.728 & 15.0 & 3.5 & 2.0 \\
\hline
\end{tabular}

As can be seen from Table 1, the comparison of the $\mathrm{W}_{(\mathrm{NiO})}: \mathrm{W}_{(\mathrm{CuO})}: \mathrm{W}_{(\mathrm{CaO})}$ and the originally designed $15: 10: 5$ in the composite oxides, there was a deviation obtained by the MGW and IMP methods, $\mathrm{W}_{\text {cuo }}$ and $\mathrm{W}_{\text {cao }}$ were decreased by more than $50 \%$ relative to the designed specific loading, but the relative mass ratio of $\mathrm{W}_{\mathrm{CuO}}$ : $\mathrm{W}_{\mathrm{CaO}}$ was in line with expectations. The composite oxides obtained by the COP method contained almost no auxiliary catalytic component $\mathrm{CuO}$, while the additive component $\mathrm{CaO}$ maintains the intended design mass ratio. This was related to the crystallization properties of the metal carbonate or the basic carbonate, and the solubility product constant in water. It's also related to $\mathrm{pH}$, and temperature, etc. Further in-depth studies will be discussed later.

Combined with the SEM-EDS results, although the amount of cocomponents and auxiliary components has been reduced, and the relative ratio still remains expected, thus, we can know that the IMP method is a good method for preparing composite oxides.

\subsection{BET surface area, BJH pore volume, $\mathrm{BJH}$ pore size results}

The results of the BET specific surface area, BJH pore volume, and BJH pore size of the different composite oxides catalysts prepared by above different methods were shown in Table 2.

From Table 2, it can be seen that MGW and IMP method have a larger specific surface area than COP method and they were more suitable for catalytic application; The BJH pore volumes of the composite oxides obtained by the three methods were not very different; The BJH pore diameters of the composite oxides obtained by the MGW and IMP methods were very small, and smaller than those of the COP method. From the viewpoint of molecular size, considered reduction amination of ethanolamine to ethylenediamine, the smaller pore size of the catalyst was the better for promoting selectivity of ethylenediamine. Therefore, we believe that the IMP method is a relatively suitable method for preparing composite oxides catalysts.
Table 2: Data of BET surface, BJH pore volume, and BJH pore diameter of oxides except carriers

\begin{tabular}{|llll|}
\hline Preparation & $\begin{array}{l}\text { BET specific surface } \\
\text { area/cm } / \mathrm{g}\end{array}$ & $\begin{array}{l}\text { The BJH pore } \\
\text { volume } / \mathrm{cm}^{3} / \mathrm{g}\end{array}$ & $\begin{array}{l}\text { BJH pore size } \\
/ \mathrm{nm}\end{array}$ \\
\hline MWG & 31.72 & 10.010 & 2.074 \\
\hline COP & 2.49 & 10.002 & 2.165 \\
\hline IMP & 22.08 & 10.006 & 2.070 \\
\hline
\end{tabular}

\subsection{Infrared spectrum results}

The infrared spectrum (IR)results of different composite oxides catalysts prepared by above different methods are shown in Figure 4. As can be seen from Figure 4,a wide-dispersion infrared characteristic absorption peak of the metastable isomer- $\mathrm{Al}_{2} \mathrm{O}_{3}$ in the composite oxides obtained by the IMP and MWG methods was shown, clearly. Due to its amorphous bulk structure, there is no single bond vibrational absorption. Comparision with the MWG method, IMP absorption slightly reduces the tendency of single peak formation, it can be seen that the relative amorphous content was reduced. There are four distinct absorption peaks of $\mathrm{NaAlO}_{2}$ on the IR absorption curve of the COP method: $902 \mathrm{~cm}^{-1} \mathrm{Al}-\mathrm{OH}$ vibration band,729 $\mathrm{cm}^{-1}, 626 \mathrm{~cm}^{-1} \mathrm{Al}(\mathrm{OH})^{4}$-vibration zone,529 $\mathrm{cm}^{-1}$ Al-O-Al vibration zone. Summarizing the above, IR analysis can tell that the IMP method is a more suitable method for preparing the catalyst.

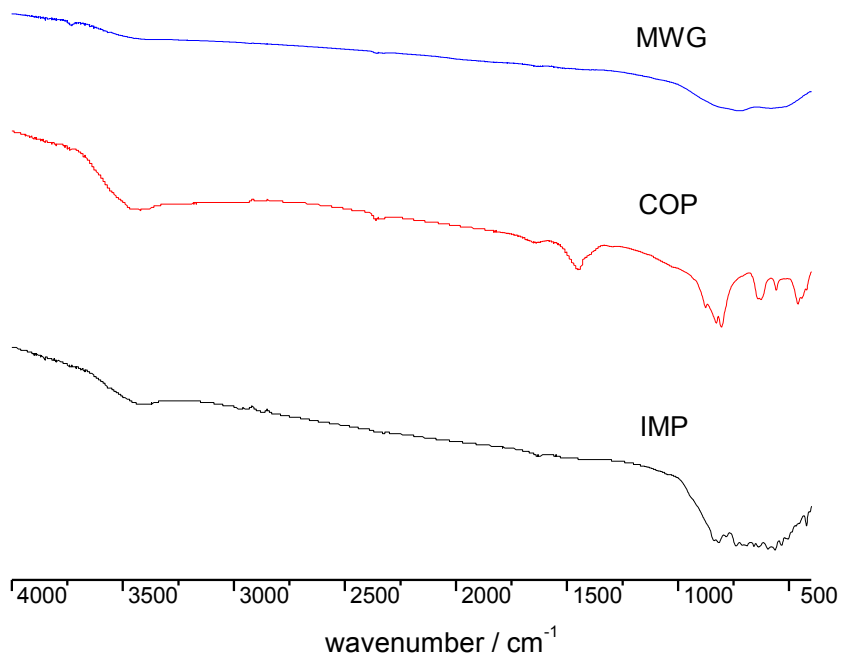

Figure 4: IR patterns of composite oxides prepared by different methods

\section{CONCLUSION}

Among the three methods of impregnation, co-precipitation and microwave-grinding, XRD,IR and SEM images show that impregnation was a suitable method for the preparation of metal composite oxides catalysts for the reduction amination of ethanolamine to ethylenediamine. According to $\mathrm{Al}_{2} \mathrm{O}_{3}: \mathrm{NiO}: \mathrm{CuO}: \mathrm{CaO}=70: 15: 10: 5$ (mass percentage)in the $\mathrm{NiO}$ $\mathrm{CuO}-\mathrm{CaO} / \mathrm{Al}_{2} \mathrm{O}_{3}$ composite oxides catalyst designed, the actual ratio was confirmed by EDS data analysis. During the impregnation process, although the amounts of auxiliary components and co-ingredients compared to the expected design have been reduced, the relative proportions of $\mathrm{CuO}$ and $\mathrm{CaO}$ remain unchanged. The concentration of impregnating solution can be increased to increase its oxides content in catalysts.

In addition, relatively large BET specific surface areas of $22.08 \mathrm{~cm}^{2} / \mathrm{g}$ and $31.72 \mathrm{~cm}^{2} / \mathrm{g}$ were obtained by the impregnation method and the microwave grinding method, respectively. And the specific surface area of only $2.49 \mathrm{~cm}^{2} / \mathrm{g}$ was obtained by coprecipitation method. The difference of BJH pore volume of the composite oxides obtained by the three methods was not large; The $\mathrm{BJH}$ pore diameter of the composite oxide obtained by the impregnation method is $2.070 \mathrm{~nm}$, which is relatively small compared to other methods. Theoretically, it was more suitable for the catalytic reaction of ethanolaminer eduction amination to ethylenediamine. The investigation of the catalytic performance of the catalyst and the design of the catalytic process are being studied. 


\section{REFERENCES}

[1] Segawa, K., Shimura, T. 2000. Effect of dealumination of mordenite by acid leaching for selective synthesis of ethylenediamine from ethanolami ne [J]. Applied Catalysis A: General, 194-195, 309-317.

[2] Chen, W., Tian, H. 2014. The Production of Ethylenediamine and Its Ma rket Condition and Prospects for Development [J]. Shandong Chemical Ind ustry, 43 (11), 85-87.

[3] Huang, C. 2013. Production Technology of Ethylenediamine and Its Ma rket Status[]]. Guangdong Chemical Industry, 40 (16), 122-124.

[4] Hanson, M.S., Gustafson, L.K.C., Lif, J. 2013. Process to prepare ethylen e amines: US, US 8563778 B2[P].

[5] Zhang, H., Yang, S., Hong, C. 2017. Synthesis of Ethylenediamine by Cat alytic Ammoniation of Ethylene Glycol [J]. Chinese Journal of Applied Che mistry, 34 (5), 557-562.

[6] Deng, X., Pei, S., Cheng, Y. 2013. Continuous Catalytic Synthesis of Ethy lenediamine from Dichloroethane and Ammonia [J]. Speciality Petrochem icals, 30 (01), 8-12.

[7] Kong, X. 2014. The Automatic Control Design for the Production Unit o $\mathrm{f}$ the Ethyleneamines project [D]. East China University of Science and Tec hnology.

[8] Liang, S., Huang, K., Peng, X. 2010. The Nature and Applications of Ethy lenediamine [J]. Enterprise Science And Technology \& Development, (10), 16-18.

[9] Li, H., Sun, G., Lei, C. 2010. Characterization and preparation of catalys $\mathrm{t}$ for ethylenediamine synthesis from ethanolamine [J]. Chemical Industry and Engineering Progress, 29 (S2), 174-178.

[10] Huang, K., Wang, Z., Sun, G. 2010. Preparation of Bamboo Fiber-reinf orced Epoxy Resin Composites and Mechanical Properties Study [J]. Tech nology \& Development of Chemical Industry, 39 (8), 36-40.

[11] Wang, Y., Yao, X., Wang, J. 2010. ResearchAdvancesinSynthesisandSe parationofEthanoldiamine [J]. Guangzhou Chemical Industry, 38 (10), 4951.

[12] Zhao, F., Yang, J., Lv, J. 2007. Study Progress on Reduction Amination Catalyst in the Synthesis of Ethylenediamine [J]. Chemical Production and Technology, 14 (6), 38-41.

[13] Yang, J., Zhao, F., Lv, J. 2007. Research advances in production of etha nol amine and its downstream products [J]. Chemical Industry and Engine ering Progress, 26 (7), 940-943.

[14] Wei, A., Li, C., Lv, J. 2014. Synthesis of Ethylene Polyamine from Etha nolamine by Gas-solid Catalytic Reaction [J]. Chemical World, 55 (4), 234237.
[15] Yang, Y., Lan, Z., Tian, B. 2012. Progress in Research of Ethylenediami ne Synthesis [J]. Petrochemical Technology, 41 (5), 603-608.

[16] Wang, D., Liu, Z., Yang, W. 2017. Catalytic Amination of Ethanolamine to Ethylenediamine over Binderless H-mordenite [J]. Fine Chemicals, 34 ( 6), 601-606.

[17] Zhang, Y., Bai, G., Yan, X., Li, Y. 2006. Amination of ethanolamine over cobalt modified H-ZSM-5 catalysts [J]. Catalysis Communications, 8 (7), 11 02-1106.

[18] Sun, G., Wei, Z., Lei, Z. 2011. GC Analysis of the Reaction Solution of P reparation of Ethylene Diamine by Reductive Amination of Ethanolamine [J]. Physical Testing and Chemical Analysis (Part B:Chemical Analysis), 47 (06), 711-712.

[19] Li, H., Sun, G., Wei, Z. 2010. Study on Ethylenediamine Synthesis from Ethanolamine by Reductive Amination Method [J]. Technology \& Develop ment of Chemical Industry, 39 (11), 6-9.

[20] Sun, J., Zhang, L., Ge, C. 2014. Comparative study on the catalytic CO o xidation properties of $\mathrm{CuO} / \mathrm{CeO}$, catalysts prepared by solid state and we $\mathrm{t}$ impregnation [J]. Chinese Journal of Catalysis, 35 (8), 1347-1358.

[21] Zeng, T., Chen, L., Bai, G. 2003. Study on a New Technique for Continu ous Syethesisof Piperazine in Fixbed-Bed Reactor [J]. Speciality Petroche micals, (04), 4-6.

[22] Ni, H. 2004. Study on the New Catalyst of Synthesis of 2-Methylpyraz ine [D]. Zhejiang University.

[23] Luo, Y., Zhou, J., You, Z. 2014. Advances in Microwave on Chemical Re actions [J]. Hans Journal of Chemical Engineering \s\&\stechnology, 04 (04 ), 45-62.

\section{ABOUT THE AUTHORS}

Xin Li(1993),He is a Master graduate student.He is mainly engaged in the research of amine catalyst.Email:10344826@qq.com.

Huan Wang(1990),She is a Master graduate student.She is mainly engage $\mathrm{d}$ in the study of the Alcohol Hydrolysis Amination Process.Email:116931 6516@qq.com.

LiyeLiu(1979),He is a master at the Jilin Institute of Chemical Technology . He is mainly engaged inthe synthesis of drugs and intermediates.

Jibo Zhang(1969),He is a professor at the Jilin Institute of Chemical Techn ology.He is mainly engaged in chemical process development and fine ch emical development, etc.Email:465419341@qq.com.

Jun Qiu(1971),He is a professor at the Jilin Institute of Chemical Technolo gy.He is mainly engaged in green fine chemical catalysis process and green synthesis technology of chemical drugs and intermediates. Email :2313522164@qq.com. 